\title{
Quantitative Trait Loci Mapping for Adult-Plant Resistance to Powdery Mildew in Bread Wheat
}

\author{
S. S. Liang, K. Suenaga, Z. H. He, Z. L. Wang, H. Y. Liu, D. S. Wang, R. P. Singh, P. Sourdille, and X. C. Xia
}

First, third, fifth, sixth, and ninth authors: Institute of Crop Science/National Wheat Improvement Center, Chinese Academy of Agricultural Sciences (CAAS), Zhongguancun South Street 12, 100081, Beijing, China; second author: Japan International Research Center for Agricultural Sciences (JIRCAS), 1-1 Ohwashi, Tsukuba, Ibaraki 305-8686, Japan; third author: CIMMYT China Office, C/O CAAS, Zhongguancun South Street 12, 100081, Beijing, China; fourth author: Northwest Sci-Tech University of Agriculture and Forestry, Yangling 712100, Shaanxi, China; seventh author: International Maize and Wheat Improvement Center (CIMMYT), Apdo, Postal-6-641, 06600 Mexico, D.F., Mexico; and eighth author: INRA Amélioration et Santé des Plantes, Domaine de Crouelle, 234, Avenue du Brézet, 63100 Clermont-Ferrand Cedex 2, France.

Accepted for publication 22 February 2006.

\begin{abstract}
Liang, S. S., Suenaga, K., He, Z. H., Wang, Z. L., Liu, H. Y., Wang, D. S., Singh, R. P., Sourdille, P., and Xia, X. C. 2006. Quantitative trait loci mapping for adult-plant resistance to powdery mildew in bread wheat. Phytopathology 96:784-789.

Powdery mildew, caused by Blumeria graminis f. sp. tritici, is a major disease to wheat (Triticum aestivum) worldwide. Use of adult-plant resistance (APR) is an effective method to develop wheat cultivars with durable resistance to powdery mildew. In the present study, 432 molecular markers were used to map quantitative trait loci (QTL) for APR to powdery mildew in a doubled haploid (DH) population with 107 lines derived from the cross Fukuho-komugi $\times$ Oligoculm. Field trials were conducted in Beijing and Anyang, China during 2003-2004 and 20042005 cropping seasons, respectively. The DH lines were planted in a randomized complete block design with three replicates. Artificial inoculation was carried out in Beijing with highly virulent isolate E20 of

leaf was evaluated four times, and the maximum disease severity (MDS) on penultimate leaf was investigated in Anyang under natural inoculation in May 2004 and 2005. The heritability of resistance to powdery mildew for MDS in 2 years and two locations ranged from 0.82 to 0.93 , while the heritability for area under the disease progress curve was between 0.84 and 0.91. With the method of composite interval mapping, four QTL for APR to powdery mildew were detected on chromosomes $1 \mathrm{AS}, 2 \mathrm{BL}, 4 \mathrm{BL}$, and 7DS, explaining 5.7 to $26.6 \%$ of the phenotypic variance. Three QTL on chromosomes 1AS, 2BL, and 7DS were derived from the female, Fukuho-komugi, while the one on chromosome 4BL was from the male, Oligoculm. The QTL on chromosome 1AS showed high genetic effect on powdery mildew resistance, accounting for 19.5 to $26.6 \%$ of phenotypic variance across two environments. The QTL on 7DS associated with the locus Lr34/Yr18, flanked by microsatellite Xgwm295.1 and Ltn (leaf tip necrosis). These results will benefit for improving powdery mildew resistance in wheat breeding programs.
\end{abstract} $B$. graminis $\mathrm{f}$. sp. tritici and the powdery mildew severity on penultimate
Powdery mildew, caused by Blumeria graminis $\mathrm{f}$. sp. tritici, is a very destructive leaf disease of common wheat (Triticum aestivum L.), which causes great yield losses in many wheat production areas of the world, especially in the regions with high rainfall and with a maritime or semi-continental climate (1). In China, the vulnerability to powdery mildew has increased significantly since the early 1980s due to the introduction of semi-dwarf cultivars and subsequent use of large amounts of fertilizers (40).

Although fungicide application is effective in controlling powdery mildew, the most economically and environmentally sound way of control is to use resistant cultivars (1). Therefore, breeding for resistance to powdery mildew is a major objective in the main wheat producing regions, such as Yellow and Huai valley and Yangtze region in China. During the past decades, the racespecific resistance genes ( $P m$ genes), conferring complete resistance caused by a hypersensitive reaction, have been used extensively. However, this type of resistance was often short lived due to the emergence of new pathogen races with matching virulence $(24,26)$. To prolong and enhance the effectiveness of race-specific resistance, gene pyramiding (36), multilines (4), and cultivar mixtures (39) were proposed and used in wheat breeding programs.

Corresponding authors: Z. H. He; E-mail address: zhhe@public3.bta.net.cn X. C. Xia; E-mail address: xiaxianchun@caas.net.cn

DOI: 10.1094/PHYTO-96-0784

(C) 2006 The American Phytopathological Society
Alternatively, partial resistance (9) was proposed for durable resistance to powdery mildew, which was characterized by a compatible interaction in all growth stages, but a lower frequency of infection, a longer latent period, a lower rate of spore production at adult-plant stage (22). This type of resistance is also called adult-plant resistance (APR) or slow mildewing that can be identified in cultivars with defeated race-specific genes or lacking known race-specific resistance genes $(8,24)$. APR to powdery mildew is more durable than race-specific resistance, which has provided durable control of powdery mildew in wheat (26), barley (11), and oat (12).

Since APR is conditioned by quantitative resistance genes (8), molecular markers associated with the genes should be a useful tool for breeding. During the past decade, a series of studies on APR to powdery mildew were carried out. Griffey and Das (7) reported two to three genes conferred APR to powdery mildew in Massey. Keller et al. (13) detected 18 quantitative trait loci (QTL) for APR to powdery mildew in a segregating wheat/spelt (Triticum spelt L.) population, which explained $77 \%$ of the phenotypic variance. Liu et al. (16) identified three QTL for APR to powdery mildew in an $\mathrm{F}_{2: 3}$ mapping population derived from Becker/ Massey, which were located on the chromosomes 1B, 2A, and $2 \mathrm{~B}$, respectively, explaining 17,29 , and $11 \%$ of the total variation for powdery mildew resistance. Chantret et al. (5) found three QTL on chromosomes 4A, 5D, and 6A, and five QTL on chromosomes $5 \mathrm{D}, 6 \mathrm{~A}, 7 \mathrm{~A}$, and $7 \mathrm{~B}$ in a doubled haploid $(\mathrm{DH})$ and $\mathrm{F}_{2: 3}$ population derived from the cross RE714/Hardi, of which the 
QTL on chromosome 5D was a major QTL, explaining 28.1 to $37.9 \%$ of phenotypic variance. Mingeot et al. (19) detected one to seven QTL for APR to powdery mildew in two DH populations from the cross between RE714 and the susceptible parents 'Festin' and 'Hardi' in different environments. They found two major QTL on chromosome 5D and at the MIRE locus that displayed stable resistance across different environments.

Fukuho-komugi (i.e., Norin 124) is a Japanese wheat cultivar with good agronomic traits and resistance to stripe rust, leaf rust, and powdery mildew $(23,33,34)$. The APR genes $\operatorname{Yr} 18, \mathrm{Lr} 34$, and other quantitative trait loci against stripe rust and leaf rust were identified in a previous study (34). The aim of this study was to identify QTL for APR to powdery mildew and their associated molecular markers in a DH population from the cross between Fukuho-komugi and Israeli wheat Oligoculm.

\section{MATERIALS AND METHODS}

Plant materials. A DH population with 107 lines used in this study was developed from a cross between Japanese wheat Fukuho-komugi and Israeli wheat Oligoculm by a wheat $\times$ maize cross technique (32). Fukuho-komugi is moderately susceptible to the predominant Chinese isolate E20 of B. graminis f. sp. tritici at seedling stage, yet is highly resistant at the adult-plant stage. Oligoculm is highly susceptible to the isolate E20 of $B$. graminis f. sp. tritici at seedling stage and moderately resistant at adultplant stage.

Field trials. During the 2003-2004 and 2004-2005 cropping seasons, the DH lines and their parents were evaluated for APR to powdery mildew, respectively, at the experimental station of the Institute of Crop Science, Chinese Academy of Agricultural Sciences (CAAS), Beijing, and the Cotton Research Institute, CAAS, Anyang, Henan Province. Field trials were conducted in a randomized complete block design with three replicates. Plots consisted of single row with a row spacing of $25 \mathrm{~cm}$ and $2 \mathrm{~m}$ in length. Approximately 150 seeds were sown in each row.

In Beijing, the DH lines and their parents were sown in the spring. The spring wheat cv. Morocco, highly susceptible to powdery mildew, was planted every 10 rows as susceptible check, and planted around the test lines to ensure ample powdery mildew inoculum. Artificial inoculation with the highly virulent isolate E20 of B. graminis f. sp. tritici was performed prior to plants reaching stem elongation. The disease severity on penultimate leaf (F-1 leaf) on 10 randomly selected plants from each line was scored based on the actual percentage of leaf area covered by powdery mildew for the first time 2 weeks after inoculation and then at weekly intervals until leaves were physiologically mature when the leaves turn yellow. Disease severity of the 10 selected plants was averaged to obtain mean powdery mildew severity for each line.

In Anyang, the seeds were sown in autumn. Jingshuang 16, a highly susceptible cultivar to powdery mildew, was planted every 10 rows and around the test lines as susceptible check and spreader. Powdery mildew severity on the penultimate leaf (F-1 leaf) of 10 randomly selected plants from each line was rated based on the actual percentage of leaf area covered by powdery mildew, when the disease severity of susceptible check cv. Jingshuang 16 reached maximum level around 18 May 2004 and 2005. Disease severity of the 10 randomly selected plants from each line was averaged to obtain mean powdery mildew severity for each line.

Statistical analysis. Relative maximum disease severity (MDS) on the penultimate leaf was calculated by dividing the MDS of each line by the MDS of the susceptible check, Morocco or Jingshuang 16. Because of the skewed distribution of the percentage of MDS on penultimate leaf among the DH lines, the MDS value was transformed into inverse sine by the formula $x=\operatorname{Sin}^{-1} \sqrt{\mathrm{MDS}}$ for subsequent analysis of variance (ANOVA) and QTL analysis. The area under the disease progress curve (AUDPC) was calculated for each line using the following formula described by Bjarko and Line (2):

$$
\mathrm{AUDPC}=\sum_{i=1}^{n}\left[\left(X_{i}+X_{\bar{i}+1}\right) / 2\right]\left(T_{i+1}-T_{i}\right)
$$

where $X_{i}$ is the disease severity on assessment date $i, T_{i}$ is the number of days after inoculation on assessment date $i$, and $n$ is the total times of disease assessments. SAS software (SAS Institute, Cary, NC) was used to compute ANOVA. Heritabilities $\left(h^{2}\right)$ were estimated from the ANOVA by the following formula (5): $h^{2}=$ $\sigma_{g}{ }^{2} /\left[\sigma_{g}{ }^{2}+\left(\sigma_{e}{ }^{2} / n\right)\right]$, where $\sigma_{g}{ }^{2}$ is the genetic variance $\left[\sigma_{g}{ }^{2}=1 / n\right.$ $\left(\mathrm{MS}_{e}-\mathrm{MS}_{g}\right)$, MS denotes mean square, $\sigma_{e}^{2}$ is the environmental variance $\left(\sigma_{e}^{2}=\mathrm{MS}_{e}\right)$, and $n$ is the number of replicates.

Map construction and QTL detection. To construct the framework map for the QTL analysis, we chose 432 loci, including 367 simple sequence repeats (SSR), 43 restriction fragment length polymorphism (RFLP), 10 random amplified polymorphism DNA (RAPD), seven inter-simple sequence repeats, two sequence tagged sites, one grain protein, one glume hair, and one Ltn loci $(33,34)$. The linkage groups were established with the software Map Manager QTXb20 (17). Genetic distances between markers were estimated using the mapping function of Kosambi (15). QTL were detected by composite interval mapping using the software Cartographer 2.5 (37). A logarithm of odds (LOD) of 2.5 was set to declare QTL as significant. The phenotypic variance $\left(R^{2}\right)$ explained by a QTL was obtained by the square of the partial correlation coefficient.

\section{RESULTS}

Distribution of MDS and AUDPC, and their correlation. The susceptible check cv. Morocco was amply infected with 80 to $90 \%$ of MDS on penultimate leaf in Beijing, and the MDS on penultimate leaf of Jingshuang 16 reached 50 to $60 \%$ in Anyang. The frequency distribution of powdery mildew severity parameters (MDS and AUDPC) in the DH lines at two locations is shown in Figure 1. The mean relative MDS of Fukuho-komugi and Oligoculm was 1.4 and $4.8 \%$ in Anyang, and 0.5 and $3.2 \%$ in Beijing, respectively. The average of relative MDS of the DH lines in Beijing over 2 years was $8.2 \%$, ranging from 0 to $70.4 \%$, while the mean relative MDS in Anyang for 2 years was $7.1 \%$ ranging from 0 to $79.0 \%$. In Beijing, the average of AUDPC over 2 years was 38.1, ranging from 0 to 307.7. ANOVA revealed a significant variation among the DH lines (Table 1). The MDS and AUDPC were significantly correlated with each other for the test in Beijing over 2 years $(r=0.90, P<0.01)$.

Heritabilities. In Anyang, the heritabilities for MDS were 0.84 and 0.82 in 2 years, respectively, while the heritabilities for MDS in Beijing over 2 years were 0.85 and 0.95 , respectively. The values of heritabilities for AUDPC in Beijing were 0.84 and 0.91 in 2 years, respectively.

QTL analysis for APR to powdery mildew. Four QTL for APR were detected in the DH population in two environments over 2 years (Table 2; Fig. 2). Based on the mean MDS of the 2003-2004 and 2004-2005 cropping seasons in Anyang, two QTL for powdery mildew resistance were found on chromosomes $1 \mathrm{AS}$ and 2BL, explaining 26.6 and $5.7 \%$ of the phenotypic variance, respectively. The additive effects of the QTL were -8.06 and -3.46 , respectively. According to the mean of MDS in Beijing in the 2003-2004 and 2004-2005 cropping seasons, four QTL were detected on chromosomes 1AS, 2BL, 4BL, and 7DS, accounting for $19.5,7.4,5.9$, and $12.0 \%$ of the phenotypic variance, respectively. The additive effects of these QTL were $-6.19,-3.64$, 3.31 , and -4.61 , respectively. With the average value of MDS from two locations during 2 years, three QTL were mapped on chromosomes 1AS, 2BL, and 7DS, explaining 8.0 to $22.3 \%$ of the phenotypic variance. The additive effects of these QTL were 
$-6.52,-3.71$, and -4.11 , respectively. Using the mean of AUDPC in Beijing in two cropping seasons, three QTL were mapped on chromosomes 1AS, 2BL, and 7DS, explaining 7.5 to $24.3 \%$ of the phenotypic variance. The additive effects of these QTL were $-32.29,-17.20$, and -18.89 , respectively. Among the QTL identified in this study, those on chromosomes $1 \mathrm{AS}, 2 \mathrm{BL}$, and 7DS were from the female parent, Fukuho-komugi, while the one on chromosomes 4BL was derived from the male parent, Oligoculm.

\section{DISCUSSION}

APR genes with minor or major but additive effects on powdery mildew were reported in the previous studies $(5,7,13,16)$.
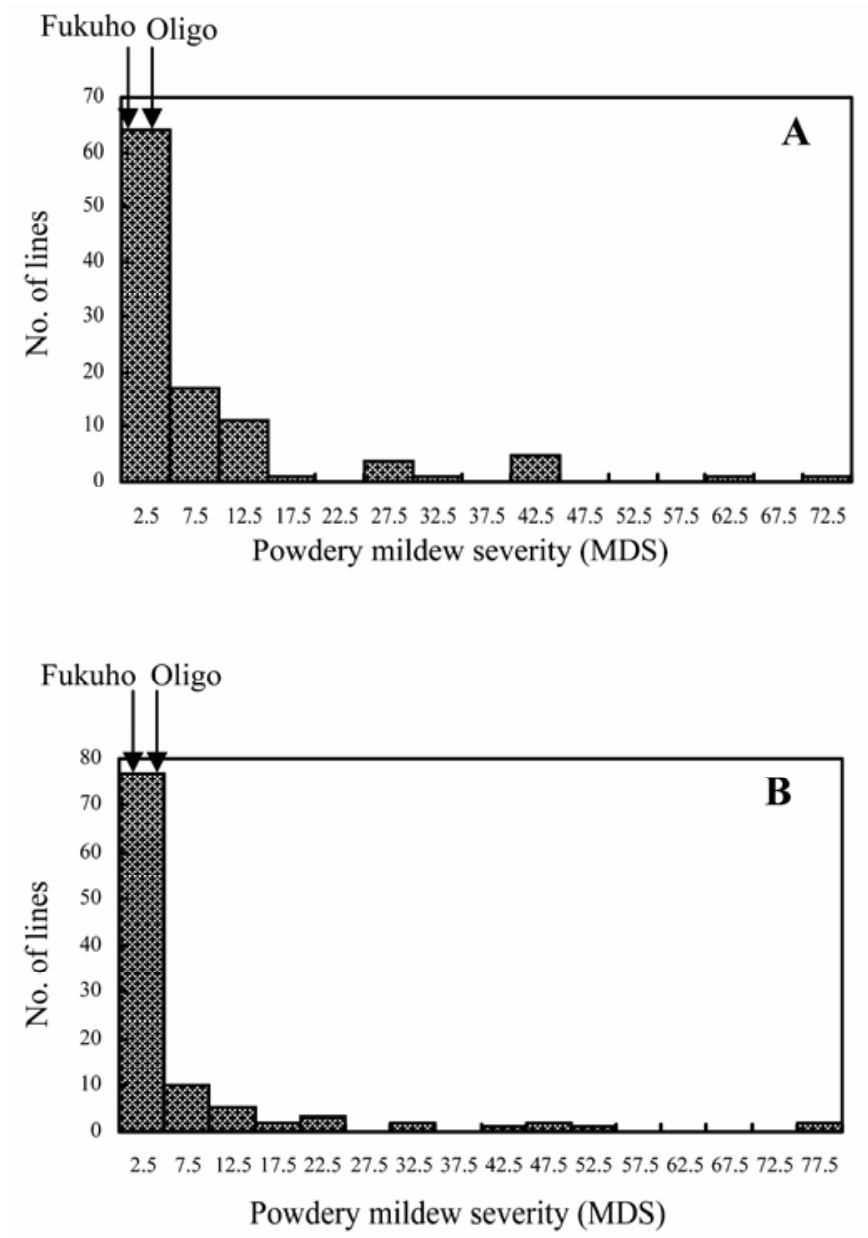

Sourdille et al. (30) found a gene Mlar conferring resistance to powdery mildew in Courtot, located on the short arm of the chromosome $1 \mathrm{AS}$ with a genetic distance of $5.2 \mathrm{cM}$ from the locus $X G l i-A 5$ coding for storage proteins. Mlar was an allele of the $P m 3$ locus $(P m 3 g)$ involved in the resistance to powdery mildew. Bougot et al. (3) mapped $P m 3 g$ in the recombinant inbred lines from the cross RE9001/Courtot and found PSP2999 cosegregated with the allele. The location of the QTL on chromosome 1AS detected in the present study is almost the same as that of the Pm3 locus, which is consistent with previous reports $(3,30)$. Originally, the powdery mildew resistance of Fukuho-komugi was derived from wheat cv. Norin 29 that possessed the resistance gene Pm3a (23). Nevertheless, the wheat line Asosan $/ 8^{*} \mathrm{CC}$ with $P m 3 a$ was highly susceptible to the predominant Chinese isolate E20 of
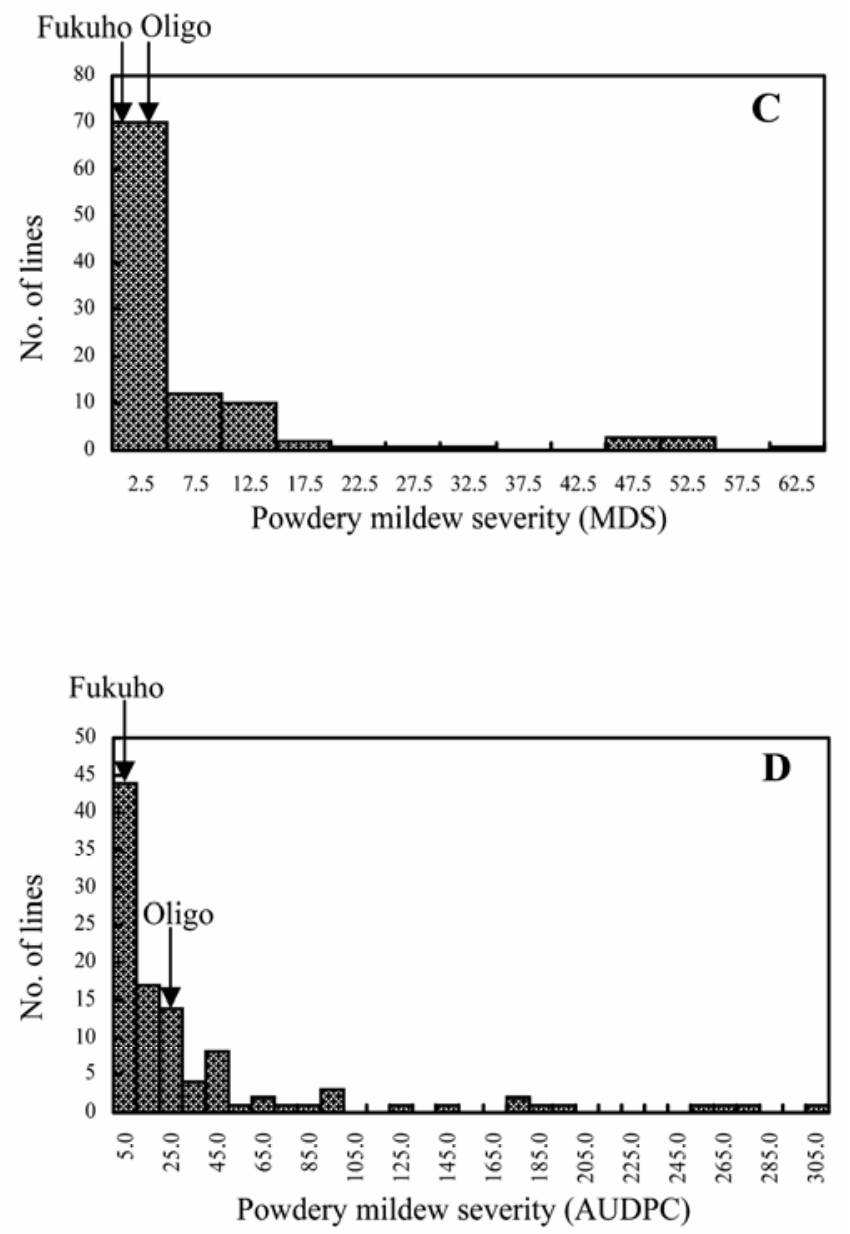

Fig. 1. A to D, Frequency distribution of powdery mildew maximum disease severity (MDS) and area under the disease progress curve (AUDPC) in the doubled haploid lines derived from the cross Fukuho-komugi/Oligoculm. A, Average of relative MDS in Beijing for 2 years, B, average of relative MDS in Anyang for 2 years, $\mathbf{C}$, average of relative MDS in two locations for 2 years, and D, average of AUDPC in Beijing for 2 years. Mean values for the parents Fukuho-komugi (Fukuho) and Oligoculm (Oligo) are indicated by arrows.

TABLE 1. Analysis of variance of relative maximum disease severity (MDS) on penultimate leaf and the area under disease progress curve (AUDPC) for powdery mildew index in the doubled haploid population derived from the cross Fukuho-komugi/Oligoculm

\begin{tabular}{|c|c|c|c|c|c|}
\hline Parameter & Source of variance & df & Mean of squares & $F$ values & $P$ \\
\hline \multirow[t]{3}{*}{ MDS } & Lines & 106 & $1,848.57$ & $15.58 * *$ & $<0.0001$ \\
\hline & Year & 1 & $9,656.77$ & $81.37 * *$ & $<0.0001$ \\
\hline & Error & 1,173 & 118.68 & & \\
\hline \multirow[t]{3}{*}{ AUDPC } & Lines & 106 & $24,258.79$ & $7.1 * *$ & $<0.0001$ \\
\hline & Year & 1 & $395,195.51$ & $115.65^{* *}$ & $<0.0001$ \\
\hline & Replicate & 2 & $17,542.82$ & $5.13 * *$ & 0.0062 \\
\hline
\end{tabular}


B. graminis f. sp. tritici at seedling stage (38). Therefore, this QTL from Fukuho-komugi is likely the residual effect of Pm3a conferring resistance to powdery mildew at adult-plant stage. Keller et al. (13) found a QTL on chromosome 7B for APR to powdery mildew in a segregating wheat/spelt ( $T$. spelta) population, and it proved to be the residual effects of Pm5. Mingeot et al. (19) reported the residual effect of the race-specific resistance genes MlRE (on 6AL) and Pm4b (on 2A) in a DH population

TABLE 2. Quantitative trait loci (QTL) detected for adult-plant resistance to powdery mildew in the doubled haploid population derived from the cross Fukuhokomugi/Oligoculm

\begin{tabular}{|c|c|c|c|c|c|c|c|}
\hline Parameter & Chromosome & Interval & Length $^{\mathrm{a}}$ & Position $^{\mathrm{b}}$ & LOD score ${ }^{c}$ & Additive effect & $R^{2 \mathrm{~d}}$ \\
\hline \multirow[t]{2}{*}{ Anyang MDS } & 1AS & Xgdm33-Xpsp2999 & 3.9 & 3.9 & 9.17 & -8.06 & $26.6 \%$ \\
\hline & 2BL & Xgwm877.1-Xwmc435.1 & 11.8 & 0 & $2.29 *$ & -3.46 & $5.7 \%$ \\
\hline \multirow[t]{4}{*}{ Beijing MDS } & $1 \mathrm{AS}$ & Xgdm33-Xpsp2999 & 3.9 & 3.9 & 8.41 & -6.19 & $19.5 \%$ \\
\hline & $2 \mathrm{BL}$ & Xwmc877.1-Xwmc435.1 & 11.8 & 4.0 & 3.57 & -3.64 & $7.4 \%$ \\
\hline & 4BL & Xgwm375-Xgwm251 & 1.1 & 1.1 & 2.89 & 3.31 & $5.9 \%$ \\
\hline & 7DS & Ltn-Xgwm295.1 & 5.7 & 0 & 5.29 & -4.61 & $12.0 \%$ \\
\hline \multirow{4}{*}{$\begin{array}{l}\text { Average of MDS } \\
\text { at two locations }\end{array}$} & & & & & & & \\
\hline & $1 \mathrm{AS}$ & Xgdm33-Xpsp2999 & 3.9 & 3.9 & 9.20 & -6.52 & $22.3 \%$ \\
\hline & $2 \mathrm{BL}$ & Xwmc877.1-Xwmc435.1 & 11.8 & 4.0 & 3.75 & -3.71 & $8.0 \%$ \\
\hline & 7DS & Ltn-Xgwm295.1 & 5.7 & 0 & 4.27 & -4.11 & $9.8 \%$ \\
\hline \multirow[t]{3}{*}{ Beijing AUDPC } & $1 \mathrm{AS}$ & Xgdm33-Xpsp2999 & 3.9 & 3.9 & 9.66 & -32.29 & $24.3 \%$ \\
\hline & 2BL & Xwmc877.1-Xwmc435.1 & 11.8 & 4.0 & 3.44 & -17.20 & $7.5 \%$ \\
\hline & 7DS & Ltn-Xgwm295.1 & 5.7 & 2.0 & 3.90 & -18.89 & $9.0 \%$ \\
\hline
\end{tabular}

a Interval length in centimorgans between the two markers flanking the peak position.

b Peak position in centimorgans from the first interval marker.

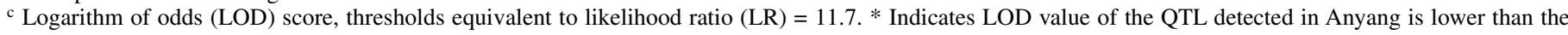
threshold 2.5.

${ }^{\mathrm{d}} R^{2}$ is the proportion of the phenotypic variance explained by the QTL.

e Maximum disease severity.

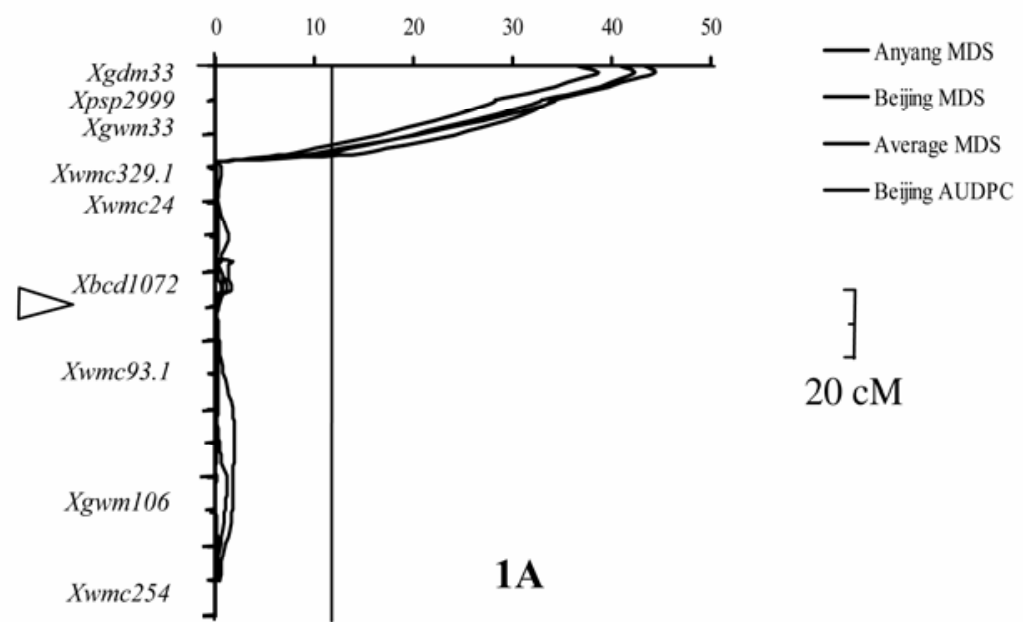

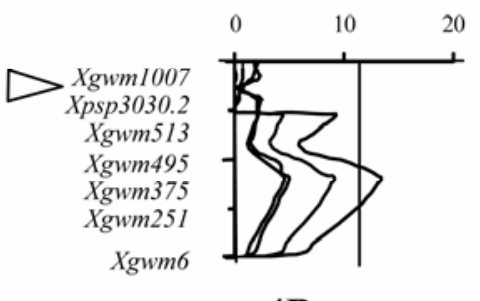

4B

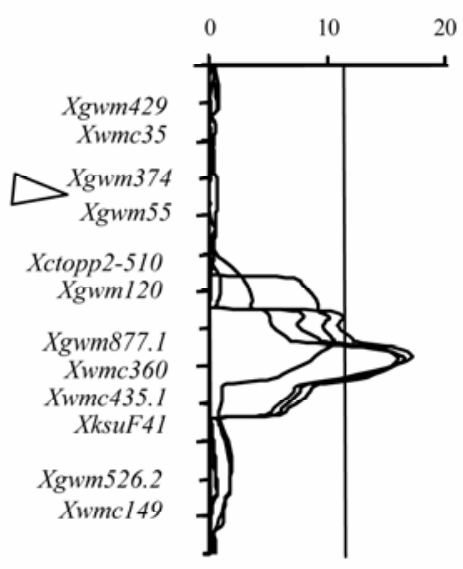

2B

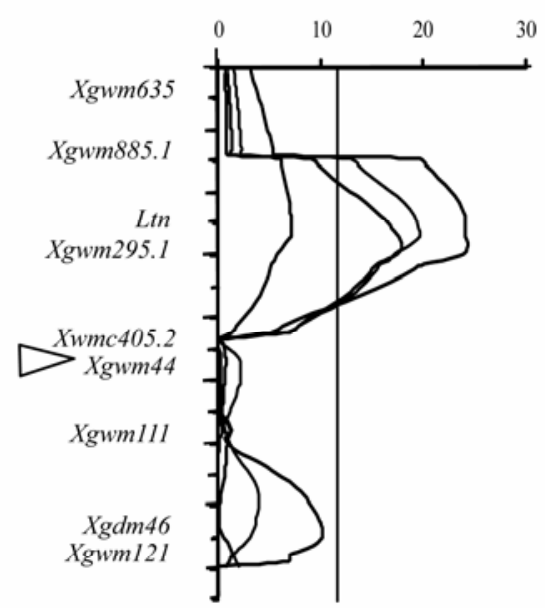

7D

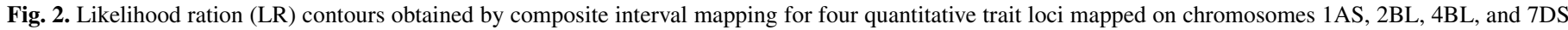

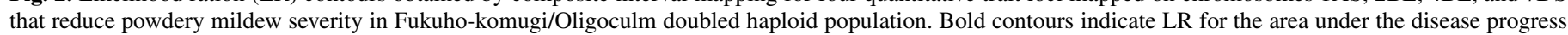
curve in Beijing. LR thresholds, equivalent to $\mathrm{LOD}=2.5$, are 11.7. Short arms are toward the top and the open arrow indicates centromere. 
from the cross RE714 $\times$ Festin. The residual effects of Pm3c and $P m 4 a$ in reducing disease severity were also reported, although the isolates were virulent to these genes at seedling stage (21). Martin and Ellingboe (18), Nagassa (20), and Royer et al. (25) also reported that Pm genes overcome by virulent isolates still contribute to partial resistance. The QTL on chromosome 2BL identified in this study was flanked by the microsatellite $X g w m 877.1$ and Xwmc435.1, Which is different from the QTL at the marker interval WG338 and Xgwm526.1 detected by Liu et al. (16) with a distance of $40 \mathrm{cM}$. Tao et al. (35) found that the gene Pm6 is located on chromosome $2 \mathrm{BL}$ and flanked by the loci Xpsr934-Xbcd135, which is close to the QTL identified in our study. Keller et al. (13) detected a QTL for powdery mildew resistance on chromosome 4BL between the RFLP markers Xpsr593b and Xpsr1112, in a segregation population from a cross of wheat with spelt. Its location is very close to that of the QTL detected in the present study. Huo et al. (10) found a major QTL conferring resistance to powdery mildew located on chromosome 7DS, flanked by the loci Xwg834-Xbcd1438, which is also close to the QTL on 7DS identified in the present study.

Fukuho-komugi displayed leaf tip necrosis (LTN) in field trials, and hence, was considered to possess Lr34/Yr18 (6,27,28). Using the same DH population as that employed in the present study, Suenaga et al. (34) detected a QTL on chromosome 7DS for resistance to both leaf rust and stripe rust, possibly due to the resistance genes Lr34/Yr18. The microsatellite locus Xgwm295.1, located almost at the peak of the likelihood ratio contours for both leaf and stripe rust severity, was closely linked to Lr34/Yr18. Lr34 and $\mathrm{Yr} 18$ were previously shown to be associated with enhanced tolerance to stem rust and Barley yellow dwarf virus infection $(14,29)$. In the present study, a QTL for powdery mildew resistance was found in the same region. This chromosomal region in wheat has now been found to be associated with resistance to five different pathogens. It indicates that the resistance genes often tend to cluster together. Association of the resistance genes is likely due to the close linkage of them, or pleitrophic effects of a same locus for resistance to different diseases. In a recent report, Spielmeyer et al. (31) also found cosegregation of powdery mildew resistance with the durable leaf and stripe rust resistance conferred by Lr34 and $\mathrm{Yr} 18$, respectively. Other researchers (M. Lillemo, unpublished data, personal communication) tested the near-isogenic lines for $L r 34$ and $L r 46$ in the genetic background of Avocet-YrA and YrLrPrll in the background of Lalbahadur and found that all three genes were associated with significantly reduced levels of leaf rust, stripe rust, and powdery mildew in comparison to their susceptible genetic backgrounds. They concluded that resistance to both rust and powdery mildew is not only confined to $\operatorname{Lr} 34$, but could be a general phenomenon of LTN-associated resistance genes (M. Lillemo, unpublished data).

Of the four QTL identified in this study, two QTL located on chromosomes $1 \mathrm{AS}$ and 2BL were stably detected across two environments. The QTL on chromosome 2BL detected in Anyang had a lower LOD score value, which may be due to the inadequate disease infection under natural inoculation. This indicated that the environment affected the infection of powdery mildew and the action of the resistance gene, which was also reported in the previous studies $(16,19)$.

The resistance to powdery mildew was estimated by different disease parameters. The correlation coefficient between mean MDS and mean AUDPC is 0.90 over 2 years in Beijing $(P<$ 0.01 ), which is consistent with the result in our previous study in the characterization of Chinese wheat cultivars (38). It indicates that the MDS on penultimate leaf is also a good indicator of APR in the field, which is suitable to be used for the characterization of APR to stripe rust in wheat breeding programs with a single scoring at an appropriate time.

\section{ACKNOWLEDGMENTS}

This project was funded by National 863 program (2003AA207090) and National Natural Science Foundation of China (30220140636).

\section{LITERATURE CITED}

1. Bennett, F. G. A. 1984. Resistance to powdery mildew in wheat: A review of its use in agriculture and breeding programmes. Plant Pathol. 33:279-300.

2. Bjarko, M. E., and Line, R. F. 1988. Heritability and number of genes controlling leaf rust resistance on four cultivars of wheat. Phytopathology 78:457-461.

3. Bougot, Y., Lemoine, J., Pavoine, M. T., Barloy, D., and Doussinault, G. 2002. Identification of a microsatellite marker associated with Pm3 resistance alleles to powdery mildew in wheat. Plant Breed. 121:325-329.

4. Browning, J. A., and Frey, K. J. 1969. Multiline cultivars as a means of disease control. Annu. Rev. Phytopathol. 7:355-382.

5. Chantret, N., Mingeot, D., Sourdille, P., Bernard, M., Jacquemin, J. M., and Dousdinault, G. 2001. A major QTL for powdery mildew resistance is stable over time and at two development stages in winter wheat. Theor. Appl. Genet. 103:962-971.

6. Dyck, P. L. 1991. Genetics of adult-plant leaf rust resistance in 'Chinese Spring' and 'Sturdy' wheats. Crop Sci. 31:309-311.

7. Griffey, C. A., and Das, M. K. 1994. Inheritance of adult-plant resistance to powdery mildew in Knox62 and Massey winter wheats. Crop Sci. 34:641-646.

8. Gustafson, G., and Shaner, G. 1982. Influence of plant age on the expression of slow-mildewing resistance in wheat. Phytopathology 72:746749.

9. Hautea, R. A., Coffman, W. R., Sorrells, M. E., and Bergstrom, G. C. 1987. Inheritance of partial resistance to powdery mildew in spring wheat. Theor. Appl. Genet. 73:609-615.

10. Huo, N. X., Zhou, R. H., Zhang, L. F., and Jia, J. Z. 2005. Mapping quantitative trait loci for powdery mildew resistance in wheat. Acta Agron. Sin. 31:692-696. (in Chinese with English abstract)

11. Jones, I. T., and Davies, I. J. E. R. 1985. Partial resistance to Erysiphe graminis f. sp. hordei in old European barley varieties. Euphytica 34:499507.

12. Jones, I. T., and Hayes, J. D. 1971. The effect of sowing date on adult plant resistance to Erysiphe graminis f. sp. avenae in oats. Annu. Appl. Biol. 68:31-39.

13. Keller, M., Keller, B., Schachermayr, G., Winzeler, M., Schmid, J. E., Stamp, P., and Messmer, M. M. 1999. Quantitative trait loci for resistance against powdery mildew in a segregating wheat $\times$ spelt population. Theor. Appl. Genet. 98:903-912.

14. Kerber, E. R., and Aung, T. 1999. Leaf rust resistance gene Lr34 associated with nonsuppression of stem rust resistance in the wheat cultivar Canthatch. Phytopathology 89:518-521.

15. Kosambi, D. D. 1944. The estimation of map distance from recombination values. Annu. Eugen. 12:172-175.

16. Liu, S. X., Griffey, C. A., and Maroof, M. A. S. 2001. Identification of molecular markers associated with adult plant resistance to powdery mildew in common wheat cultivar Massey. Crop Sci. 41:1268-1275.

17. Manly, K. F., Cudmore, R. H., Jr., and Meer, J. M. 2001. Map Manager QTX, cross-platform software for genetic mapping. Mammal. Genome 12:930-932.

18. Martin, T. J., and Ellingboe, A. H. 1976. Differences between compatible parasite/host genotypes involving the Pm4 locus of wheat and the corresponding genes in Erysiphe graminis f. sp. tritici. Phytopathology 66:1435-1438.

19. Mingeot, D., Chantret, N., Baret, P. V., Dekeyser, A., Boukhatem, N., Sourdille, P., Doussinault, G., and Jacquemin, J. M. 2002. Mapping QTL involved in adult plant resistance to powdery mildew in the winter wheat line RE714 in two susceptible genetic backgrounds. Plant Breed. 121:133-140.

20. Nagassa, M. 1987. Possible new genes for resistance to powdery mildew, Septoria glume blotch and leaf rust of wheat. Plant Breed. 98:37-46.

21. Nass, H. A., Pedersen, W. L., MacKenzie, D. R., and Nelson, R. R. 1981. The residual effects of some "defeated" powdery mildew resistance loci in cereals. Theor. Appl. Genet. 93:1078-1082.

22. Parlevliet, J. E., and van Ommeren, A. 1975. Partial resistance of barley to leaf rust, Puccinia hordei. II. Relationship between field trials, micro plot tests and latent period. Euphytica 24:293-303.

23. Peusha, H., Hsam, S. L. K., and Zeller, F. J. 1996. Chromosomal location of powdery mildew resistance genes in common wheat (Triticum aestivum L. em. Thell.) 3. Gene Pm22 in cultivar Virest. Euphytica 91:149152.

24. Roberts, J., and Caldwell, R. 1970. General resistance (slow mildewing) 
to Erysiphe graminis f. sp. tritici 'Knox' Wheat. (Abstr.) Phytopathology 60:1310.

25. Royer, M. H., Nelson, R. R., Mackenzie, D. R., and Diehle, D. A. 1984. Partial resistance of near-isogenic wheat lines compatible with Erysiphe graminis f. sp. tritici. Phytopathology 74:1001-1006.

26. Shaner, G. 1973. Evaluation of slow-mildewing resistance of Knox wheat in the field. Phytopathology 63:867-872.

27. Singh, R. P. 1992. Association between gene Lr34 for leaf rust resistance and leaf tip necrosis in wheat. Crop Sci. 32:874-878.

28. Singh, R. P. 1992. Genetic association of leaf rust resistance gene Lr34 with adult plant resistance to stripe rust in bread wheat. Phytopathology 82:835-838.

29. Singh, R. P. 1993. Genetic association of gene $B d v l$ for tolerance to Barley yellow dwarf virus with genes Lr34 and Yr18 for adult plant resistance to rusts in bread wheat. Plant Dis. 77:1103-1106.

30. Sourdille, P., Röbe, P., Tixier, M. H., Doussinault, G., Pavoine, M. T., and Bernard, M. 1999. Location of $P m 3 g$, a powdery mildew resistance allele in wheat, by using a monosomic analysis and by identifying associated molecular markers. Euphytica 110:193-198.

31. Spielmeyer, W., McIntosh, R. A., Kolmer, J., and Lagudah, E. S. 2005. Powdery mildew resistance and $\operatorname{Lr} 34 / \mathrm{Yr} 18$ genes for durable resistance to leaf and stripe rust cosegregate at a locus on the short arm of chromosome 7D of wheat. Theor. Appl. Genet. 111:731-735.

32. Suenaga, K., and Nakajima, K. 1993. Segregation of genetic markers among wheat doubled haploid lines derived from wheat $\times$ maize crosses. Euphytica 65:145-152.

33. Suenaga, K., Khairallah, M., William, H. M., and Hoisington, D. A. 2005. A new intervarietal linkage map and its application for quantitative trait locus analysis of "gigas" features in bread wheat. Genome 48:65-75.

34. Suenaga, K., Singh, R. P., Huerta-Espino, J., and William, H. M. 2003. Microsatellite markers for genes $\operatorname{Lr} 34 / \mathrm{Yr} 18$ and other quantitative trait loci for leaf rust and stripe rust resistance in bread wheat. Phytopathology 93:881-890.

35. Tao, W. J., Liu, D. J., Liu, J. Y., and Chen, P. D. 2000. Genetic mapping of the powdery mildew resistance gene Pm6 in wheat by RFLP analysis. Theor. Appl. Genet. 100:564-568.

36. Vanderplank, J. E. 1968. Disease Resistance in Plants. Academic Press, New York.

37. Wang, S., Basten, C. J., and Zeng, Z. B. 2005. Windows QTL Cartographer v2.5. Statistical Genetics. North Carolina State University.

38. Wang, Z. L., Li, L. H., He, Z. H., Duan, X. Y., Zhou, Y. L., Chen, X. M., Lillemo, M., Singh, R. P., Wang, H., and Xia, X. C. 2005. Seeding and adult-plant resistance to powdery mildew in Chinese bread wheat cultivars and lines. Plant Dis. 89:457-463.

39. Wolfe, M. S., and Barrett, J. A. 1977. Population genetics of powdery mildew epidemics. Annu. New York Acad. Sci. 287:151-163.

40. Wu, Z. S. 1990. Breeding for wheat disease resistance. Pages 235-272 in: Wheat Breeding. Z. S. Wu, ed. Agric. Pub. Press of China, Beijing. 